general managers. Aspirin and streptokinase remain the treatment of choice in myocardial infarction; there seems little justification for adding heparin."' This is not good news for those patients who, after myocardial infarction, have to proceed to urgent or semiurgent cardiac surgery for unstable angina or other aspects of the infarction.

The effect of aspirin on platelets results in difficult and sometimes uncontrollable and fatal bleeding. Cobbe's conclusions are not good news for cardiac surgeons or managers or for patients if they have to sit around in hospital for several days waiting for "urgent" surgery for their unstable angina while the effects of the aspirin wear off. Nor is this good news for the cardiologists, cardiac surgeons, and haematologists who have to decide when it is safe to operate.

I have two questions. Firstly, is it not possible to use a non-steroidal anti-inflammatory agent other than aspirin which would have a similar effect on platelets but a much shorter half life so that cardiac surgery could proceed safely within 24 hours of the drug being stopped? Secondly, could members of the British Cardiac Society and the British Society of Thoracic and Cardiovascular Surgeons produce guidelines on this contentious aspect of cardiac surgery?

MP HOLDEN

Freeman Hospital,

Newcastle upon Tyne NE7 7DN

1 Cobbe SM. ISIS 3: the last word on thrombolysis? BMF 1992:304:1454-5. 6 June.

AUTHOR'S REPLY, - It is important to emphasise that only a small minority of patients who have received thrombolytic treatment for acute myocardial infarction require cardiac surgical intervention. In the few patients with persisting unstable angina after myocardial infarction, withdrawal of aspirin before coronary artery bypass grafting may increase the risk of acute coronary occlusion and reinfarction. As a result of this the cardiac surgeons in this hospital undertake coronary bypass grafting on such patients without stopping aspirin. Their recent study indicated that the median postoperative blood loss was increased by $490 \mathrm{ml}$ in patients receiving $150 \mathrm{mg}$ of aspirin compared with controls.' This was associated with a median increase in the transfusion requirement of two units of red cell concentrates, and fresh frozen plasma, platelets, or cryoprecipitate were required in $20 \%$ of patients treated with aspirin compared with $5 \%$ of controls $(p<0 \cdot 01)$. There was no increase in the median postoperative hospital stay.

Use of other non-steroidal anti-inflammatory drugs has not been validated in terms of their effect on mortality after myocardial infarction. Furthermore, experimental studies suggest that these drugs may impair the healing of an infarct and lead to its expansion and an increased risk of cardiac failure.

I do not disagree with Holden's view that aspirin increases bleeding after coronary bypass grafting. In my view, the small risk of excess surgical bleeding associated with aspirin has to be accepted as the price to be paid for avoiding preoperative coronary occlusion in the small proportion of patients who develop unstable angina after thrombolytic treatment for acute myocardial infarction. These considerations should not be allowed to detract from the clear benefit associated with treatment with aspirin.

S M COBBE

Department of Medical Cardiology,

Roval Infirmary,

(jlasgow (331 $2 \mathrm{ER}$

1 Taggart DP, Siddiqui $A$, Wheatley DJ. Low-dose preoperative aspirin therapy, postoperative blood loss, and transfusion requirements. Ann Thorac Surg 1990;50:425-8.

2 Jugdutt BI. Delayed effects of early infarct-limiting therapic: on healing after myocardial infarction. Circulation 1985;72 $907-14$
Diarrhoea, dysentery, and food poisoning

AUTHOR'S REPLY, - J K Anand raises a valid point. My intention, however, was to point out the role of notification and control of infection in the overall management of infectious diarrhoea and not to discuss specific cases. Owing to the similar presentation of many of these diseases, I consider barrier nursing prudent for patients with these diseases on admission to hospital pending a firm microbiological diagnosis. After diagnosis the infection control procedure can be reviewed and revisedhence the need to consult the local infection control policy, as I stated in my letter.

King's College Hospital,

A J HAY London SE5 9RS

AUTHOR'S REPLY, $-\mathrm{J}$ K Anand raises a valid point. My intention, however, was to point out the role of notification and control of infection in the overall management of infectious diarrhoea and not to discuss specific cases. Owing to the similar presentation of many of these diseases, I consider barrier nursing prudent for patients with these diseases on admission to hospital pending a firm microbiological diagnosis. After diagnosis the infection control procedure can be reviewed and revisedhence the need to consult the local infection control policy, as I stated in my letter.

King's College Hospital,

A J HAY

London SE5 9RS

\section{Selective serotonin reuptake inhibitors}

EDITOR, - In his editorial on selective serotonin reuptake inhibitors J Guy Edwards presents a conservative view of the current situation with regard to the prescription of antidepressants. ' $\mathrm{He}$ comments that "those recently marketed in Britain include fluvoxamine, fluoxetine, sertraline, and paroxetine." Fluvoxamine has been available since 1987 and fluoxetine since 1989 . He rightly states that in terms of efficacy selective serotonin reuptake inhibitors are not superior to tricyclic antidepressants, but the profile of their side effects does offer advantages for patients.

Edwards says that "clinical anecdotes ... do not provide good evidence of cause and effect" yet reports several single cases of adverse reactions. He mentions that prescription event monitoring showed that 24 women had become pregnant while taking a selective serotonin reuptake inhibitor but does not state at what point the pregnancy occurred. None of these drugs is recommended in pregnancy, but patients commonly become pregnant during treatment.

With particular reference to fluoxetine Edwards makes an erroneous statement - that six weeks is required before treatment with a monoamine oxidase inhibitor is started. The datasheet states that at least five weeks should elapse.

I believe that many psychiatrists would take issue with Edwards over his suggestion that the "main uses of selective serotonin reuptake inhibitors would seem to be in clinically depressed patients who are unable to tolerate tricyclic antidepressants and those with associated troublesome obesity or heart disease." The selective serotonin reuptake inhibitors have been an enormous advance not only in the treatment of depression but in developing the understanding of other disorders such as anxiety, panic disorder, obsessive compulsive disorder, and bulimia nervosa

Disappointingly, Edwards concludes with a price comparison and the comment, "Whether they are worth the extra cost is something that individual doctors and patients will have to decide." It sounds as though Edwards has already made up his mind, which presumably also means that of his patients.

DEBBIE HARRISON

Lilly Industries,

Basingstoke,

Hampshire RG21 2SY

1 Edwards JG. Selective serotonin reuptake inhibitors. BMf 1992;304:1644-6. (27 June.)

EDITOR,-If there are two classes of drug that are equally effective in treating depression, one of which is cheap but highly toxic and the other of which is safe but perceived to be expensive, a doctor cannot decide between the two on economic grounds. This ethical crisis, however, faces general practitioners daily when balancing their patients' welfare.

I believe that it is only a matter of time before a general practitioner is asked to defend himself or herself, in a civil suit brought by relatives of a patient who has committed suicide, against charges of having negligently provided that patient with the means to commit suicide. If I was that general practitioner and I had not at least tried one of the newer selective serotonin reuptake inhibitors I would find it difficult to defend my position. The process of litigation is exceedingly slow, and by the time such a case was resolved there would be thousands more in the pipeline.

J Guy Edwards, I believe, has overlooked these overwhelming moral and economic reasons why we should have professional agreement that tricyclic antidepressants are no longer acceptable as first line antidepressant treatment.

SO FRADD

Sneinton Health Centre,

Sneinton,

Nottingham NG2 +P]

Edwards JG. Selective serotonin reuptake inhibitors. $B M$ 1992;304:1644-6. (27 June.)

\section{Adrenaline in allergic emergencies}

EDIToR,-We think that G B Smith and B L Taylor's comments on the treatment of allergic emergencies ${ }^{1}$ in reply to our original letter ${ }^{2}$ are misleading. They conclude that "when adrenaline is required in an anaphylactic emergency it should be given ... intravenously." We are concerned about the implications of such a recommendation. Firstly, it is contrary to current recommendations in the British National Formulary. ${ }^{3}$ In the section on allergic emergencies (section 3.4.3) in the formulary the use of adrenaline is emphasised: "IMPORTANT. Intravenous route is for cardiac resuscitation only." In the section on sympathomimetics (section 2.7) it is similarly emphasised "IMPORTANT. For acute anaphylaxis use intramuscular route."

Smith and Taylor say that "vasodilatation is a major pathophysiological characteristic of anaphylaxis," but this is not always the case, and venous access can be difficult, particularly outside hospital. Furthermore, intravenous adrenaline has been reported to lead to serious adverse reactions, and this concern cannot just be dismissed by the statement, "Concerns for the potential dangers . . are largely misfounded." This is particularly relevant as there are only limited reports on its use other than to point out the problems encountered with intravenous administration. ${ }^{+}$Smith and Taylor's conclusion may result in a trend towards intravenous administration of adrenaline in allergic emergencies without due consideration of the potential hazards.

In conclusion, we do not entirely disagree with 
Smith and Tavlor as the intravenous route may be useful in certain circumstances. Until conclusive advantages have been shown for the intravenous route in allergic emergencies, however, we recommend adherence to the guidelines in the British National Formulary and preferential use of the intramuscular route.

GREGORY Y H LII MALCOLM J METCALFE

Department of Cardiology,

Stobhill Gencral Hospital

Glasgow G21 3L'W

1 Smith GB, Taylor BL. Adrenaline in allergic emergencies. B.117 1992;304:1635. 20 Jun

2 Lip GYH, Metcalfe MJ. Adrenaline in allergic emergencies. B.MY 1992:304:1443. (30) Mas

BMA and Royal Pharmaceutical Society of Great Britain. Britsh national formulary No 23 (. Harch 1992). London: BMA and Pharmaceutical Press, 1992.

+ Roberts-Thomson P, Heddle R, Kupa A. Adrenaline and anaphylaxis. Hed 7 . A ust 1985;142:708.

\section{HIV antibodies in babies}

EnITor, - Pietro Portincasa and colleagues describe what seems to be a very sensitive radioimmune western blot method for detecting $\operatorname{IgA}$ and $\operatorname{IgM}$ antibodies to HIV in the serum of HIV infected neonates born to seropositive mothers.' They conclude that it will discriminate early between babies who are and are not infected with HIV. There may, however, be reasons other than established HIV infection for the presence of $\operatorname{IgA}$ and IgM antibodies to HIV in the neonatal circulation, and they would detract from the value of tests for these antibodies at birth as indicators of transmission of HIV from mother to infant.

One possible explanation for the detection of $\operatorname{IgA}$ and $\operatorname{Ig} M$ antibodies to HIV in neonates is that maternal IgM and IgA molecules cross the placenta and are detected by the sensitive assays of HIV antibodies now available, such as that used by Portincasa and colleagues. We use antibody capture assays for HIV specific $\operatorname{IgG}, \operatorname{IgA}$, and $\operatorname{IgM}$. We detect $\operatorname{IgG}$ with HIV $1+2$ GACELISA (Wellcozyme) and IgA and IgM by substituting anti-c and anti- $u$ for anti- $\gamma$ in the solid phase of the same kit. With these assays we have often detected HIV antibodies of all three immunoglobulin classes in infected people. For example, we recently examined the blood of 37 parturient seropositive mothers: all 37 had detectable HIV specific IgG and $\operatorname{IgA}$, and 35 had specific $\operatorname{Ig} M$. We also tested blood from their newborn babies. Those babies born to mothers with $\mathrm{IgA}$ reactivity (optical density:cut off reactivity) $\geqslant 8$ and IgM reactivity $\geqslant 7$ had detectable $\operatorname{IgA}$ and $\operatorname{Ig} M$ (optical density:cut off reactivity $\geqslant 1$ ), whereas in those babies whose mothers had weaker $\operatorname{IgA}$ or $\operatorname{Ig} M$ reactivity neither specific IgA nor IgM was detectable.

Though not all of these results may be specific, the most likely interpretation of the findings is that, contrary to dogma based on insensitive assays, specific IgA and $\operatorname{Ig} M$ do cross the placenta. When concentrations of these antibodies in the mother are sufficiently high and a sensitive assay is used the antibodies are detectable in the infant. The mothers with the highest IgA and IgM HIV antibody concentrations may be those who have the most intense viraemia. If so, the virus would be most likely to be transmitted to the infant when specific $\operatorname{Ig} A$ and $\operatorname{Ig} M$ reactivities are high in the mother and detectable in the infant; but the essential point is that the $\operatorname{IgA}$ and $\operatorname{IgM}$ antibodies detected in the infant may have been passively acquired, not actively produced, and cannot therefore be due to infection in the infant even though they may be suggestive of it. If, as has been hypothesised, transmission of HIV takes place "at the end of pregnancy or at delivery,"' the infected neonate is unlikely to have an active antibody response at birth.

Evidence from longitudinal study of babies born
Detection of $I g A, I g M$, and $I g G$ antibodies to HIV in infants aged $\leqslant 3$ months and $>3$ months who were born to seropositive mothers and whose eventual HIV infection status was known

\begin{tabular}{lcc}
\hline & $\leqslant 3$ Months & $>3$ Months \\
\hline \multicolumn{3}{c}{ Infected } \\
IgA & $(\mathrm{n}=12)$ & $(\mathrm{n}=24)$ \\
$\operatorname{IgM}$ & 4 & 20 \\
$\operatorname{IgG}$ & 5 & 14 \\
& 12 & 24
\end{tabular}

$\begin{array}{lcc} & \text { Not infected } \\ & (\mathbf{n}=37) & (\mathbf{n}=12) \\ \operatorname{IgA} & 12 & \\ \operatorname{IgM} & 14 & 7 \star \\ \operatorname{lgG} & 37 & 7^{\star}\end{array}$

*Aged 5-11 months; the five infants who were negative for $\operatorname{IgG}$ antibody were aged 9-17 months.

to seropositive mothers supports the view that IgA and IgM HIV antibodies detected very early in life are derived from the mother and do not necessarily indicate infection. We have investigated babies infected with HIV (positive for HIV DNA on polymerase chain reaction, antibody persistently found in second year of life, or clinical signs) and babies not infected (table). We found IgA and IgM antibodies almost as commonly in those of 3 months and younger who did not later show evidence of infection as in those who did. In the older babies, however, we detected $\operatorname{IgA}$ and $\operatorname{Ig} M$ antibodies only in those who were subsequently shown to be infected. This agrees with other recent reports.

Though detection of IgA antibody to HIV after 3 months of age strongly suggests active infection, we doubt whether the presence of $\operatorname{IgA}$ or $\operatorname{IgM}$ antibodies earlier in life is a reliable marker of infection or their absence a sign of freedom from infection.

J A CONNELL

J V PARRY

PHLS Virus Reference Division, P P MORTIMER

Central Public Health Laboratory,

I.ondon NW9 5 HT

Regional Virus Laboratory

City Hospital, Edinburgh EH10 5SB

S M BURNS

Bugando Medical Centre

A KLOKKE

Mwanza, Tanzania

A DE ROSSI

C GIAQUINTO

Department of Paediatrics

Padua University,

1 Portincasa P Conti G, Re MC Chezzi C. Detection of IgA and

Portincasa P, Conti G, Re MC, Chezzi C. Detection of IgA and
IgM antibodies to HIV-1 in neonates by radioimmune western IgM antibodies to HIV-1 in neonates by radioinm
blotting. BMF 1992;304:1539-42. (13 June.)

2 Krivine A, Firtion G, Cao L, Francoual C, Henrion R, Lebon $P$. HIV replication during the first weeks of life. Lance 1992;339:1187-9.

3 W'ieblen BJ, Lee FK, Cooper ER, Landesman SH, McIntosh K, Harris JS, et al. Early diagnosis of HIV infection in infants by detection of IgA HIV antibodies. Lancet 1990;335:988-90.

4 Quinn TC, Kline RL, Halsey N, Hutton N, Ruff A, Butz A, et al. Early diagnosis of perinatal HIV infection by detection of viral-specific IgA antibodies. FAMA 1991;266:3439-42.

5 Landesman S, Weiblen B, Mendez H, Willoughby A, Goedert $\mathrm{JL}$, Rubinstein A, et al. Clinical utility of HIV-IgA immunoblot assay in the early diagnosis of perinatal HIV infection. $7 A M A$
a assay in the early
1991;266:3443-6.

\section{Treatment of Hodgkin's lymphoma}

EDITOR,-In writing on treatment and delayed morbidity in Hodgkin's lymphoma Patrice Carde states that "Patients unsuitable for transplantation include those in whom complete remission has never been achieved, those who have had previous extensive irradiation, or, in some centres, those in second complete remission." Our view, based on experience of treating 155 patients with Hodgkin's disease at this centre and the data reported to the European Bone Marrow Transplant Group's register of autologous bone marrow transplantation in lymphoma, is that the first two parts of this statement are incorrect.

The concept that patients refractory to induction therapy (but not those who have a very good partial response) have a prognosis so poor as not to justify the use of autologous bone marrow transplantation comes from a multicentre study of non-Hodgkin's lymphoma, ${ }^{2}$ and our experience confirms this view. This principle, however, cannot be applied to the selection of patients for high dose therapy and autologous bone marrow transplantation in Hodgkin's disease. Our evidence for this is that in the patients treated at this centre with chemotherapy with carmustine, etoposide, cytarabine, and melphalan and autologous bone marrow transplantation the progression free survival at five years of patients who had never achieved remission was $40 \%$ compared with $50 \%$ for the whole group. In 1000 patients reported to the European Bone Marrow Transplant Group the progression free survival for patients with Hodgkin's disease who had never achieved remission was 29\% at five years compared with $34 \%$ for the whole group (European Bone Marrow Transplant Group, 1992).

With regard to the exclusion of patients who have had extensive previous irradiation, again our experience is that this is rarely a problem when a conditioning regimen of high dose chemotherapy without total body irradiation is used before transplantation. In patients in whom the bone marrow reserve has been depleted by extensive irradiation of areas of active haemopoiesis stem cells obtained from peripheral blood may be used in place of bone marrow.'

We believe that high dose therapy and autologous bone marrow transplantation should be considered in Hodgkin's disease: (1) when patients fail to achieve remission with induction therapy with either a MOPP regimen (mustine, vincristine, procarbazine, and prednisolone) or a regimen of MOPP alternating with ABVD (doxorubicin, bleomycin, vinblastine, and dacarbazine) or a regimen similar to either of these; $(2)$ when patients relapse within six months of initial treatment; and (3) when patients relapse after treatment with two or more modalities.

\section{A MCMILLAN R CHOPRA}

R PEARCE A H GOLDSTONE D C LINCH

Department of Haematology

University College Hospital,

London WC1E 6HX

1 Carde P. Hodgkin's lymphoma. II. Treatment and delaved morbidity. BMf 1992;305:173-6. (18 July.)

2 Philip T, Armitage JO, Spizzer G, Chauvin F, Jagannath $S$, Cahn J-Y, et al. High dose therapy and ABMT after failure of conventional therapy in adults with intermediate grade
or high grade non-Hodgkin's Iymphoma. $N$ Engl g Med or high grade nom

3 Gribhen JG, Goldstone AH, Linch DC, Taghipour G, McMillan AK, Souhami RL, et al. Effectiveness of high-dose combination chemotherapy and autologous bone marrow transplantation for patients with non-Hodgkin's lymphomas who are still responsive to conventional-dose therapy. I Clin Oncol 1989;7:1621-9.

4 Chopra R, McMillan AK, Sanda Y, Blair S, Taghipour G, Patterson KG, et al. Single centre study of BEAM and ABMT in 155 patients with relapsed or resistant Hodgkin's disease. Blood 1991;78(suppl 1):1152.

5 Kessinger A, Armitage JO, Smith DM, Landmark JD, Bierman PJ, Weisenburger DD. High dose therapy and autologous peripheral blood stem cell transplantation for patients with lymphoma. Blood 1989;74:1260.

\section{Problem drug use in general practice}

EDIToR,-John Cohen and colleagues report the experience of one general practice in central London with a large population of patients misusing drugs long term. ${ }^{1}$ I have similar experience, 